\title{
Enantioselective Ring-Opening Polymerization of rac-Lactide Dictated by Densely Substituted Aminoacids
}

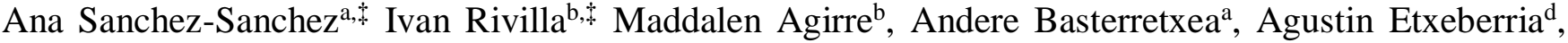 \\ Antonio Veloso $^{\mathrm{a}}$, Haritz Sardon ${ }^{\mathrm{a}, \mathrm{c}, \mathrm{d}}$, David Mecerreyes ${ }^{\mathrm{a}, \mathrm{c}^{*}}$ and Fernando P. Cossio ${ }^{\mathrm{b}, \mathrm{e}^{*}}$ \\ a POLYMAT University of the Basque Country UPV/EHU, Joxe Mari Korta Center, Avda. Tolosa 72, 20018 Donostia/San \\ Sebastian, Spain. \\ ${ }^{\mathrm{b}}$ Departamento de Quimica Organica I and Instituto de Innovación en Química Avanzada (ORFEO-CINQA), University of \\ the Basque Country (UPV/EHU), $\mathrm{P}^{\circ}$ Manuel Lardizabal 3, 20018 Donostia/San Sebastian, Spain. \\ ${ }^{c}$ Ikerbasque, Basque Foundation for Science, E-48011 Bilbao, Spain. \\ d Department of Polymer Science and Technology, Institute of Polymer Materials, University of the Basque Country \\ UPV/EHU, P ${ }^{\circ}$ Manuel Lardizabal 3, Donostia/San Sebastian, 20018, Spain. \\ ${ }^{\mathrm{e}}$ Donostia International Physics Center (DIPC), $\mathrm{P}^{\mathrm{o}}$ Manuel Lardizabal 4, 20018 Donostia/San Sebastian, Spain.
}

\section{Supporting Information Placeholder}

\begin{abstract}
Although organometallic catalysts have shown great ability to promote these polymerization reactions, their substantial toxicity and other drawbacks are accelerating the development of organic catalysts. To date, organic catalysts have demonstrated some ability to promote stereocontrolled polymerizations. However, none of them has been able to promote efficiently different stereochemical outcomes depending on the chirality of the organic catalyst. In this work we report for the first time the chirality transfer from catalyst to polymer in the ringopening polymerization (ROP) of rac-lactide (rac-LA). We have polymerized rac-LA using diastereomeric densely substituted aminoacids (2S,3R,4S,5S)-1-methyl-4-nitro-3,5diphenylpyrrolidine-2-carboxylic acid (endo-6) and (2S,3S,4R,5S)-1-methyl-4-nitro-3,5-diphenylpyrrolidine-2-

carboxylic acid (exo-6), combined with 1,8-Diazabicyclo[5.4.0]undec-7-ene (DBU) as co-catalyst. Both diastereoisomers not only showed the ability to synthesize enriched isotactic polylactide with a $\mathrm{P}_{\mathrm{m}}$ higher than 0.90 at room temperature, but they were also able to preferentially promote the polymerization of one of the isomers ( $\mathrm{L}$ or $\mathrm{D}$ ) with respect to the other. Thus, exo-6 preferentially polymerized L-lactide while endo-6 preferred D-lactide as substrate. DFT calculations were conducted to investigate the origins of this unique stereocontrol in the polymerization, providing a mechanistic insight and confirming that the chirality of the catalyst is able to define the stereochemistry of the monomer insertion.
\end{abstract}

Introduction

Since the discovery of synthetic polymers in the mid $20^{\text {th }}$ century, there has been a continuous search of control over the different aspects of polymerization such as kinetics, stereoregularity, dispersity, sequence distribution, functionality or macromolecular architecture..$^{1-3}$ Stereocontrol is very important in polymerization reactions because the stereoregularity is a necessary condition for crystalline polymers which often have an array of mechanical properties superior to those of the corresponding nonstereoregular polymers. ${ }^{4}$ Given the excellent performance and almost limitless opportunities of ligand/metal combinations, it is not surprising that transition metals and organometallic catalysts have dominated the field of stereocontrolled polymerizations. ${ }^{5-8}$ Stereocontrol polymerization can be performed by two different mechanisms: chain end control and enantiomorphic site control. ${ }^{1}$ In the former mechanism, the chirality of the propagating chain end bound to the catalyst regulates the chirality of the next monomer insertion, while in the latter the chirality of the catalyst, and not the chain end, dictates the next monomeric unit insertion.

One of the polymer families where the stereocontrol has attracted great interest is the family of polyesters, ${ }^{9}$ specially polylactide (PLA). PLA is nowadays the most popular example of renewable, biocompatible and biodegradable polymer. ${ }^{2,10,11}$ Interestingly, PLA's mechanical properties and biodegradability are linked to its microstructure and hence poly(L-lactide) posses a melting point $\left(\mathrm{T}_{\mathrm{m}}\right)$ close to $160{ }^{\circ} \mathrm{C}$ whereas the atactic one is an amorphous polymer with low mechanical properties. ${ }^{12}$ Metal alkoxides and some achiral organometallic catalysts have shown to be efficient to promote the synthesis of stereoregular PLA. ${ }^{13,14}$

Although metal based catalysts are considered much more versatile than non-metal based ones, their substantial toxicity is accelerating the development of organic catalysts. ${ }^{2,15,16}$ Some organic catalysts such as N-heterocyclic carbenes, ${ }^{17,18}$ phosphazenes ${ }^{19}$ or (R)-binaphthol derived phosphoric acids ${ }^{20}$ have recently shown the ability to promote the stereocontrolled polymerization of rac-LA. In all these cases the stereocontrol is given via chain end control mechanism. ${ }^{2}$ Consequently, the catalyst is not able to promote different stereochemical outcomes by modifying the chirality of the catalytic species. More recently the group of Chen have prepared some new bifunctional chiral catalysts based on $\beta$-isocupreidine core, thiourea and chiral binaphthyl-amine. They showed the ability to promote different stereochemical outcomes by flipping the chirality of the catalyst. These results showed significant advances to previous works reported in the literature. However, using the $\mathrm{S}$ version of the catalyst much inferior kinetic resolution was obtained. ${ }^{21}$, Therefore, the investigation of an organic catalyst family able to dictate the monomer insertion (L-LA or D-LA from the racemic mixture) as a function of the chirality of the catalyst is actively searched. 

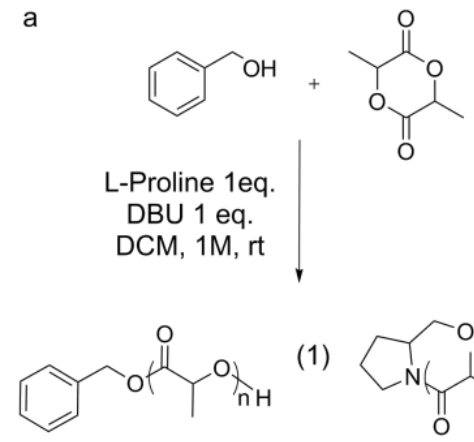

(1)

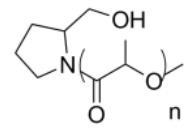

(2)

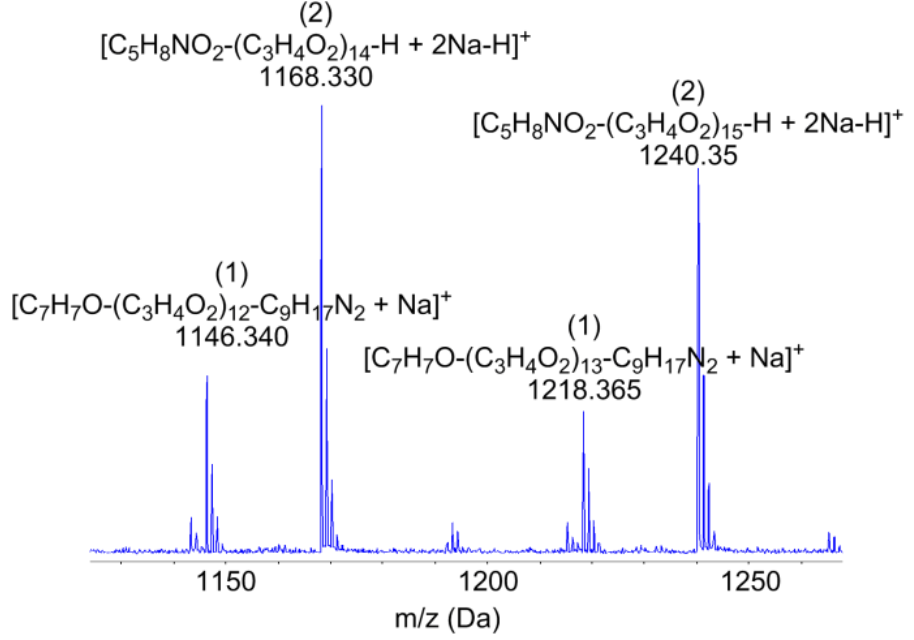

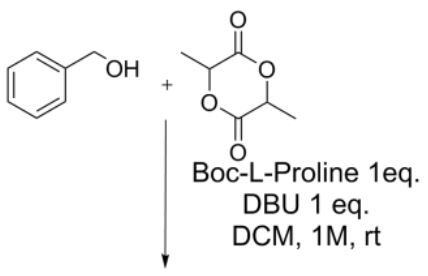

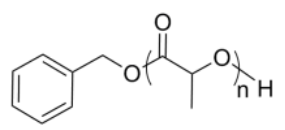

(1)

$\left[\mathrm{C}_{7} \mathrm{H}_{7} \mathrm{O}-\left(\mathrm{C}_{6} \mathrm{H}_{8} \mathrm{O}_{4}\right)_{33}-\mathrm{H}+\mathrm{Na}\right]^{+}$ 4885.864

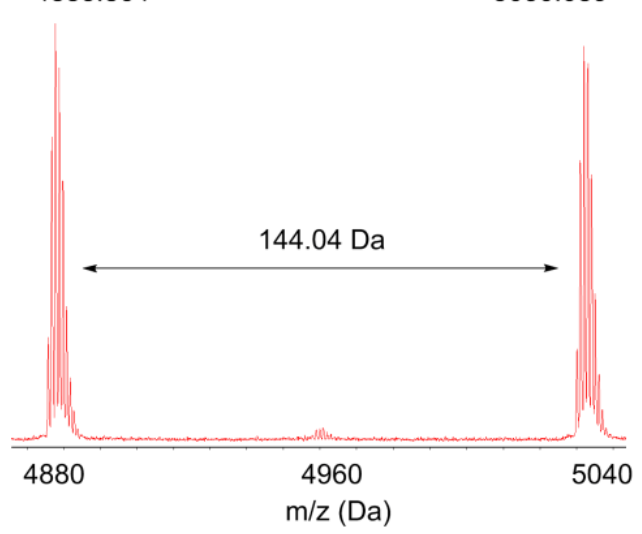

(1) $\left.\mathrm{H}_{8} \mathrm{O}_{4}\right)_{34}-\mathrm{H}+\mathrm{Nal}^{+}$ 5030.089

Figure 1. MALDI-TOF spectra enlargements where exact mass and the assigment of each molecule is disclosed for the polymerization of rac-LA using benzyl alcohol as initiator and DBU as co-catalyst a) in the presence of L-proline b) in the presence of Boc-L-proline.

In our search to find a catalyst able to promote stereocontrolled polymerizations we turned to nature for inspiration. Nature accomplishes outstandingly enantioselective modifications using macromolecules such as enzymes. Interestingly, Barbas, List and MacMillan, among others, ${ }^{22-25}$ showed that enzymes such as aldolases can be reduced to minimalistic analogues such as natural monomeric amino acids without losing the essentials of the catalytic activity.

Among them, proline amino acid is considered one of the most successful catalysts because it promotes many different enantioselective catalytic processes such as the aldol, 26,27 Mannich, ${ }^{28}$ Michael, ${ }^{29,30}$ and Diels-Alder reactions. ${ }^{31}$ Although the use of amino acid based organocatalysts in the stereocontrolled synthesis of small organic molecules has been broadly studied, when we focus on the synthesis of polymers the number of scientific articles using prolines is incomprehensibly diminished. To the best of our knowledge prolines only have shown to be efficient to promote the polyaldol reaction without promoting any stereoregularity. ${ }^{32-33}$

In this paper we report an organic catalyst which shows the ability to transfer the chirality to the polymer and to promote stereocontrolled ROP of lactide. For that purpose, we prepared Nprotected densely substituted prolines by means of catalytic asymmetric $(3+2)$ cycloadditions and subsequent transformations. We have investigated how modifying the chirality of two distal centers of these prolines, high stereoselectivity could be promoted in the polymerization of D-lactide or L-lactide starting from a racemic mixture. Density Functional Theory (DFT) calculations were also conducted to provide mechanistic insight into the ROP process in the presence of these densely substituted aminoacids.

\section{Results and Discussion}

As a first test, we investigated the commercially available Lproline (L-Pro) aminoacid as potential catalyst for the ROP of racLA (Table 1, Entry 1). Although L-proline can act as acid or base catalyst, reaction of rac-LA in the presence of L-Pro and benzyl alcohol as initiator did not lead to polymerization even at elevated temperatures. After this unsuccessful attempt, we envisioned a more efficient ROP, using a co-catalyst inspired by the work of Hedrick et al. ${ }^{34}$ The idea relies on forming strong acid / base complexes for the ring opening polymerization of lactide using the carboxylic acid or the amine groups of L-Pro with a base or an acid respectively, without having any negative effect on the polymerization. A variety of co-catalysts were screened together with L-Pro, from strong bases such as 1,8diazabicyclo[5.4.0] undec-7-ene (DBU) to strong acids such as triflic acid (TfOH) (SI section, TableS1). ${ }^{35}$ We followed the reaction by ${ }^{1} \mathrm{H}$ NMR and only when L-Pro was combined with DBU full conversion was achieved (Table 1, Entry 2). Nevertheless, the experimental molecular weight $\left(\mathrm{M}_{\mathrm{n}}=700 \mathrm{~g} \mathrm{~mol}^{-}\right.$ ${ }^{1}$ ) was much lower than the targeted one $\left(\mathrm{M}_{\mathrm{n}}=7300 \mathrm{~g} \mathrm{~mol}^{-1}\right)$. This fact was indicating that besides acting as a catalyst, L-proline / DBU complex might be participating in the initiation process of the polymerization. 


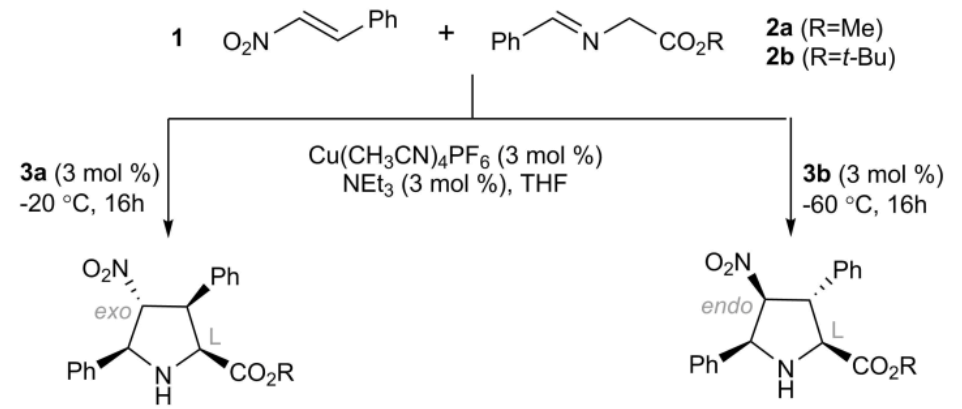

exo-4a: R=Me (85\%); dr: 95:5; ee $97 \%$

endo-4b: $\mathrm{R}=t-\mathrm{Bu}(57 \%)$; dr: 90:10; ee $99 \%$

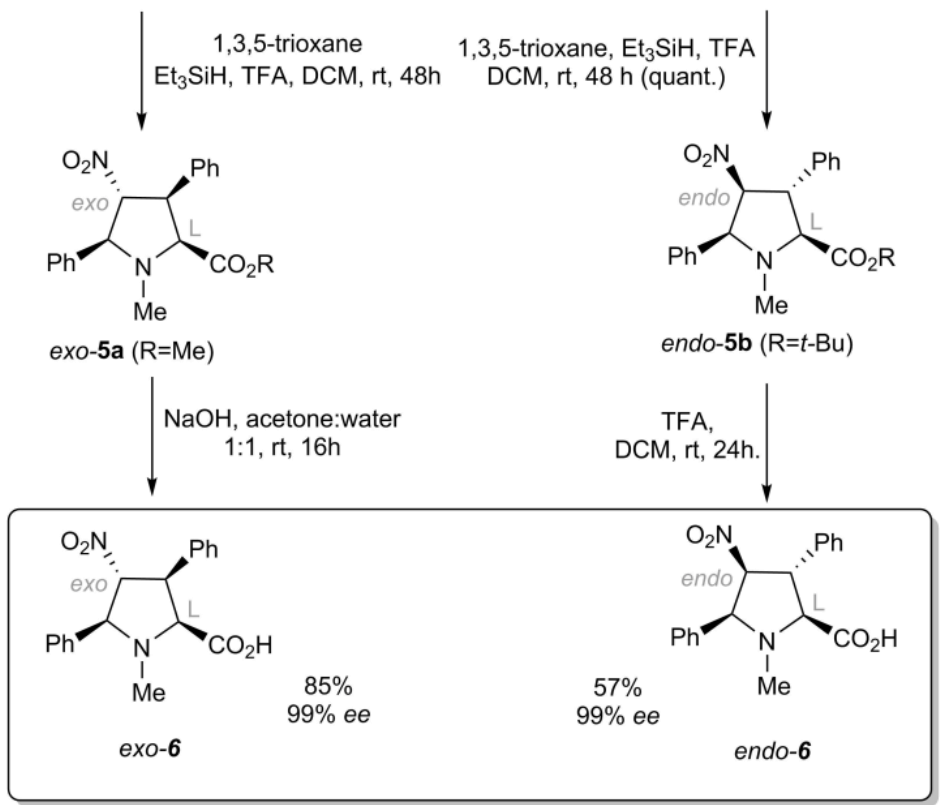

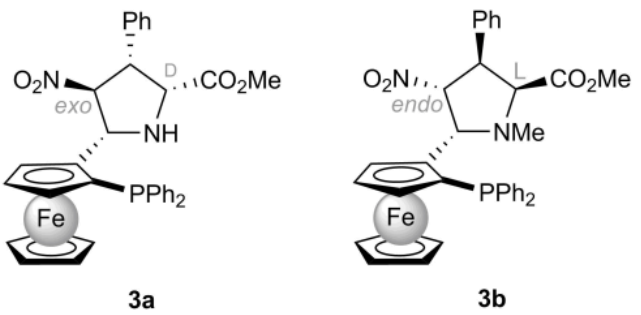

$c$

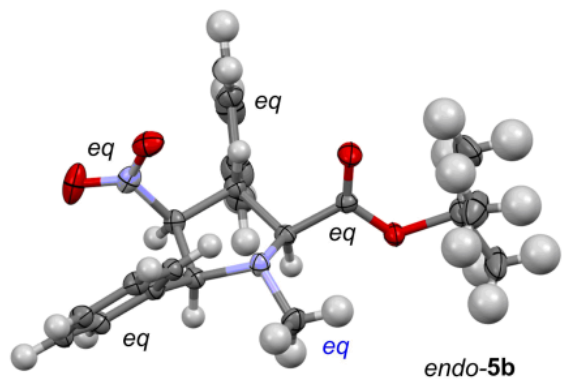

d

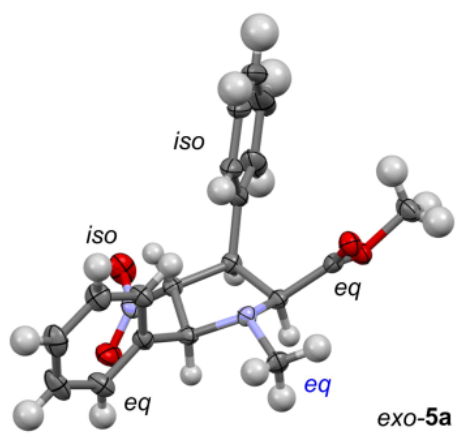

Figure 2. a) Synthesis of unnatural endo- and exo-N-methylated prolines 6. b) Chiral ligands $3 a$,b required for the asymmetric (3+2) cycloaddition between nitroalkene $\mathbf{1}$ and imines $\mathbf{2 a}, \mathbf{b}$ to yield pyrrolidines $\mathbf{4}$. c, d) Structures of organocatalysts exo-5a and endo-5b as determined by X-ray diffraction analysis.

Then, the resulting polymer was analyzed by ${ }^{1} \mathrm{H}$ NMR (SI, Figure S8) and MALDI-TOF spectrometry (Figure 1a and SI, Figure S12). As expected, together with the signal attributed to benzyl alcohol chain ends - observed at $7.44 \mathrm{ppm}$ - another set of signals attributed to L-proline protons were observed at $4.45,3.45$ and $2.05 \mathrm{ppm}$, thus confirming L-proline incorporation into the polymeric chains. Moreover, MALDI-TOF experiments confirmed the presence of two main different initiating species: the benzyl alcohol and the L-proline. These results led us to conclude that the amino group of L-Pro is initiating the ROP of LA as observed before for $\varepsilon$-caprolactone. ${ }^{33}$

Given the negligible strength of protected amines, we foresaw that N-protected prolines should not initiate the ROP of rac-LA while maintaining its catalytic activity. Thus, L-Pro was replaced by commercially available protected version, Boc-L-Pro for the polymerization of rac-LA (Table 1, Entry 3). Again, the polymerization only occurred in the presence of DBU co-catalyst. In this case, when we measured the molecular weight $v s$ conversion (SI section, Figure S6) we found a good relation between the theoretical and experimental. Furthermore, experimental molecular weight $\left(\mathrm{M}_{\mathrm{n}}=8000 \mathrm{~g} \mathrm{~mol}^{-1}\right)$ was similar to the targeted one $\left(7300 \mathrm{~g} \mathrm{~mol}^{-1}\right)$ and the dispersity (Đ) was quite narrow, with a measured value of 1.2. To further verify the endgroup and the controlled nature of the polymerization, ${ }^{1} \mathrm{H}$ NMR
(SI, Figure S9) and MALDI-TOF experiments were carried out (Figure $1 \mathrm{~b}$ and SI Figure S13). As expected, only the signals attributed to benzyl alcohol chain ends at $7.44 \mathrm{ppm}$ were observed. These results were confirmed by MALDI-TOF experiments where the corresponding end groups and only one set of peaks or distributions separated by $144 \mathrm{~g}$. $\mathrm{mol}^{-1}$ — associated with the lactide monomer unit- were detected. Finally we investigated the potential of this catalyst to prepare higher molecular weight PLA. Therefore we targeted higher polymerization degree $(\mathrm{n}=100)$. We found that experimental molecular weight $\left(\mathrm{M}_{\mathrm{n}}=23000 \mathrm{~g} \mathrm{~mol}^{-1}\right)$ was similar to the targeted one (Table 1, Entry 14 and SI, Figure S21).

Although the Boc protected L-Pro / DBU complex exhibited the ability to promote the controlled ROP of rac-LA, the main goal of our study was to promote stereocontrolled polymerizations. Thus, the microstructures of the PLA samples produced using rac-LA were determined by analyzing ${ }^{13} \mathrm{C}$ NMR signal intensities of the methine region using Bernoullian statistics. ${ }^{20}$ According to the data shown in Table 1, Boc-L-Pro/DBU complex exhibited some isotactic selectivity $\left(\mathrm{P}_{\mathrm{m}}=0.65\right)$ while $\mathrm{DBU}$ alone did not exert any significant stereocontrol and an essentially atactic material was obtained $\left(\mathrm{P}_{\mathrm{m}}=0.50\right)$ (Table 1, Entry 4$)$. On the other hand, using the method of Coudane et al. ${ }^{36}$ the average of the enantiomerically pure repeating units along the polymer chain was found to be 6 
using Boc-L-Pro. These stereoselectivity values are promising but still far from those observed in other stereocontrolled

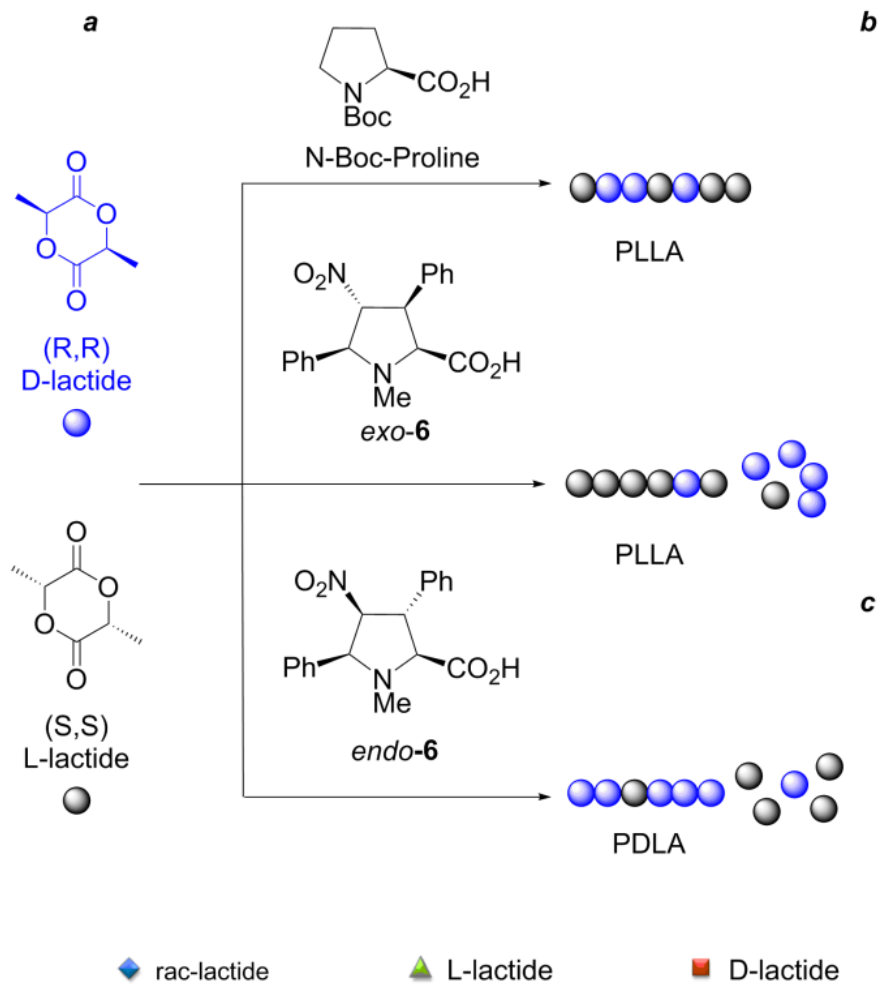

polymerizations, which show $\mathrm{P}_{\mathrm{m}}$ values higher than $0.85 .^{2}$

b

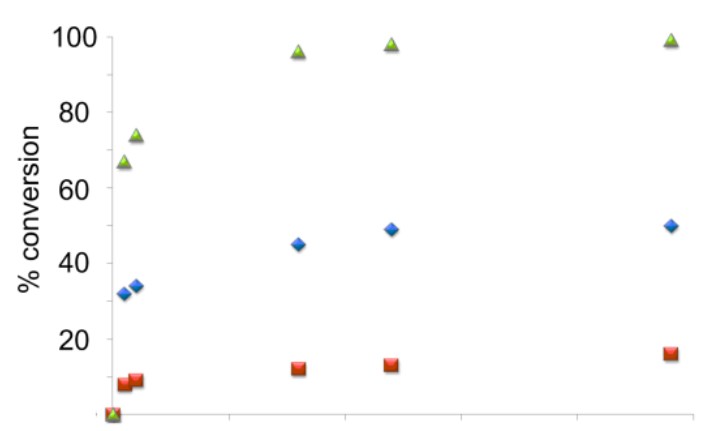

endo-6

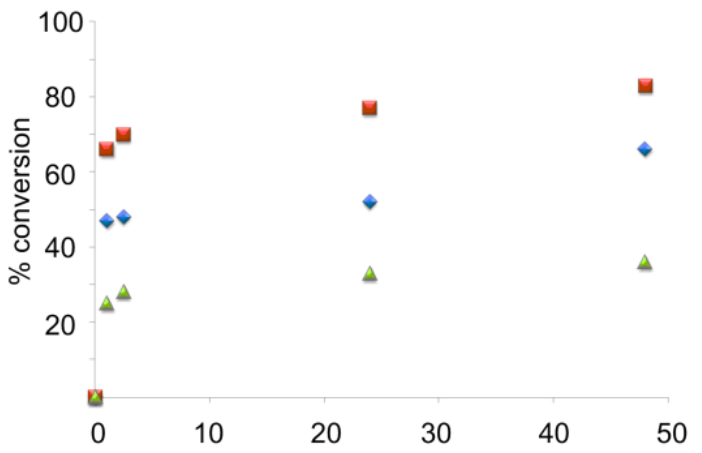

Figure 3.a) Schematic representation of the rac-LA polymerization in the presence of the 3 different N-protected prolines used in this study in DCM at r.t using DBU as co-catalyst and $\mathrm{BnOH}$ as initiator. Polymerization kinetics of L, D and rac-LA monomers in the presence of b) exo-6 or c) endo-6 in DCM at r.t using DBU as co-catalyst and BnOH as initiator.

In view of these results, we decided to prepare and explore densely substituted prolines for the enantioselective polymerization of rac-LA. These unnatural amino acid derivatives can incorporate up to four chiral centers in the pyrrolidine ring while commercially available prolines could have only one or two. ${ }^{27}$ This high number of chiral centers in a reduced molecular volume could permit to concentrate many chiral induction effects in the neighborhood of the LA unit participating in one given polymerization step. This strong chiral induction was utilized by some of us in aldol reactions to yield opposite enantiomers, promoted by remote effects. ${ }^{37}$ This anticipated the potential to obtain enhanced stereochemical outcomes by modifying the chirality and the nature of the substituents at the different positions of the corresponding organocatalyst. In order to synthesize endo- and exo-N-substituted densely substituted prolines 6 gathered in Figure $2 \mathrm{a}$, we first obtained $(3+2)$ cycloadducts $\mathbf{4}$ by 1,3-dipolar reactions between imines $\mathbf{2 a , b}$ and nitroalkene $\mathbf{1}$, catalyzed by $\mathrm{Cu}(\mathrm{I})$ complexes derived from enantiopure ligands 3a,b (Figure 2b). N-methylation of these densely substituted pyrrolidines was carried out in the presence of trifluroacetic acid and triethylsilane. The structures of endo- and exo-N-methylated esters $\mathbf{5 a , b}$ was confirmed by X-ray diffraction analysis (Figures 2c,d). Finally, basic or acidic cleavage of the ester moieties yielded organocalysts exo-6 and endo-6, respectively. Full details about the preparation and characterization of these catalysts are given in the SI section.

Next, the catalytic activity of these unnatural endo- and exo-Nsubstituted prolines was investigated for the ROP of L-Lactide (L-
LA), D-Lactide and racemic lactide (rac-LA here after) in dichloromethane (DCM) at room temperature using benzyl alcohol as the initiator (Figure 3a). First we explored the catalytic activity of exo-6 for the polymerization of L-LA. As expected, the polymerization did not occur when exo-6 was used as the sole catalyst (SI section, Table S1) and only when DBU co-catalyst was added we were able to promote the polymerization (Table 1 , Entry 5).

The ROP conditions for L-LA were surveyed by varying catalyst concentration and solvent and we found that using a monomer/initiator/catalyst ratio of $50 / 1 / 1$ we were able to reach full conversion in $24 \mathrm{~h}$ at room temperature (Table 1, Entry 6). As in the previous case, exo-6/DBU complex exhibited the ability to promote the controlled ROP of L-LA as observed by the endgroup fidelity confirmed by ${ }^{1} \mathrm{H}$ NMR and MALDI-TOF experiments (SI section, Figure S14). Furthermore, an experimental molecular weight $\mathrm{Mn}=8300 \mathrm{~g} \mathrm{~mol}^{-1}$ was observed, which was similar to the targeted one $\left(\mathrm{Mn}=7300 \mathrm{~g} \mathrm{~mol}^{-1}\right)$. In addition, the dispersity (Đ) was narrow again showing a value of 1.2 .

Besides the polymerization of L-LA, we carried out the polymerization of rac-LA (mixture of L-LA and D-LA) in the presence of exo-6 using the same monomer/initiator/catalyst ratio of 50/1/1 (Table 1, Entry 7). At the initial stages of the ROP, the rac-LA proceeded selectively to polymer derived from L-LA, but beyond a conversion of $40 \%$ the polymerization substantially slowed down, and the reaction stopped around $50 \%$ conversion 
(Figure 3b). It seemed that exo-6 had preference towards one of the isomers showing enantiomeric selectivity during the polymerization. To confirm this fact, we performed the same polymerization but using D-LA (Table 1, Entry 8). Surprisingly, the polymerization

Table 1. Polymerization of lactide (LA) with different catalysts (Cat.) at r.t.

\begin{tabular}{|c|c|c|c|c|c|c|c|}
\hline entry & Monomer & Catalyst & {$[\mathrm{LA}] /[\mathrm{BnOH}] /[\mathrm{Cat}]$} & Conv. $(\%)^{\mathrm{a}}$ & $\mathrm{M}_{\mathrm{n}}(\mathrm{SEC})\left(\mathrm{g} \cdot \mathrm{mol}^{-1}\right)^{\mathrm{b}}$ & $\mathrm{PDI}^{\mathrm{c}}$ & $P_{m}{ }^{d}$ \\
\hline 1 & rac- LA & L-Pro & - & - & - & - & - \\
\hline 2 & rac- LA & L-Pro/DBU & $50 / 1 / 5$ & $<98$ & 700 & 1.5 & - \\
\hline 4 & rac- LA & DBU & $50 / 1 / 5$ & $<98$ & 12200 & 2.1 & 0.50 \\
\hline 5 & L-LA & $e x_{0}-6 / \mathrm{DBU}$ & $50 / 1 / 5$ & 100 & 6100 & 1.4 & 1.00 \\
\hline 7 & rac- LA & $e x x_{-6} / \mathrm{DBU}$ & $50 / 1 / 1$ & 50 & 3300 & 1.1 & 0.96 \\
\hline 8 & D-LA & $e x_{0}-6 / \mathrm{DBU}$ & $50 / 1 / 1$ & 20 & - & - & 1.00 \\
\hline 9 & rac- LA & endo-6/DBU & $50 / 1 / 1$ & 51 & 3100 & 1.2 & 0.90 \\
\hline 13 & rac- LA & exo-6/endo- $6 / D B U$ & $50 / 1 / 1$ & $<98$ & 10200 & 1.2 & 0.60 \\
\hline 14 & L-LA & Boc-L-Pro/DBU & $100 / 1 / 2$ & $<98$ & 23000 & 1.3 & 1.00 \\
\hline
\end{tabular}

was much slower and after $48 \mathrm{~h}$ we were able to reach only $20 \%$ conversion (Figure $3 \mathrm{~b}$ ), being unable to get high molecular weight polymer (Table 1 , entry 8 ). These results are congruent with the fact that the catalyst dictates the entrance of the next monomeric unit and suggested that the chirality of the catalyst is the dominating factor determining the stereocontrol. To further investigate the mechanism, we performed the same experiments using the analogous endo-6. Interestingly, the opposite behavior was observed (Table 1, Entry 9, 10 \& 11). In this case, endo-6 showed much higher preference towards D-LA rather than towards L-LA (Figure 3c).

To further confirm and quantify the ability of our organic catalysts to promote stereocontrolled ROP processes, the different reaction mixtures were analyzed. To this end, the corresponding crude polymeric material was precipitated in cold methanol and the residual monomer was recovered to analyze the unreacted monomer using chiral HPLC measurements. The HPLC chromatograms showed that in the presence of exo-6, L-LA was preferentially polymerized due to the disappearance of the signal associated to this $(\mathrm{S}, \mathrm{S})$ monomer. Meanwhile, in the case of endo6, the opposite behavior was observed (SI, Figure S24-S28). Figure 3 shows a schematic representation of the polymerization process. As observed in the presence of a racemic mixture of DLA and L-LA, exo-6 promoted the polymerization of L-LA obtaining highly stereoregular poly(L-lactide) (PLLA), while in the case of endo-6 highly stereoregular poly(D-lactide) (PDLA) could be achieved (Figure 3). Apparently, endo- and exo-Nmethylated prolines were able to preferentially promote the polymerization of one of the enantiomers with respect to the other.
Nevertheless, we wanted to compare our results with other enantioselective polymerizations of rac-LA. For that purpose we analyzed the ${ }^{13} \mathrm{C}$ NMR signal intensities of the carbonyl region and methine region using Bernoullian statistics (Figure 4) of the obtained polymers. According to the data shown in Figure 4 and Table 1, both endo- and exo-N-methylated prolines showed excellent isotactic selectivities, with $\mathrm{P}_{\mathrm{m}}=0.90$ and $\mathrm{P}_{\mathrm{m}}=0.96$, respectively for rac-LA (Figure 4, SI, Figure S10). Moreover, in order to definitely assign the $\mathrm{P}_{\mathrm{m}}$ values of the obtained polymers the analysis of the homonuclear ${ }^{1} \mathrm{H}$ NMR spectra of the methine region was carried out (SI, Figure S11) and confirmed the excellent control of the polymerization. According to the data shown in Figure 4, SI section and Table 1, both endo- and exo-Nmethylated prolines showed excellent isotactic selectivities, with $\mathrm{P}_{\mathrm{m}}=0.90$ and $\mathrm{P}_{\mathrm{m}}=0.96$, respectively for rac-LA. It is worth noting that these are the highest values reported in the literature for organic catalysts at room temperature. Previous organic catalysts such as $\mathrm{N}$-heterocyclic carbenes 17,18 showed a $\mathrm{P}_{\mathrm{m}}=0.59$, phosphazenes ${ }^{19}$ a $\mathrm{P}_{\mathrm{m}}=0.72$ or $(\mathrm{R})$-binaphthol derived phosphoric acids a $\mathrm{P}_{\mathrm{m}}=0.86 .{ }^{20}$ Most importantly, most of the previous examples incorporated preferentially L-LA. In our case we were able to show for the first time high selectivity towards both Llactide but also D-lactide just by switching the chirality of the distal centers of the catalyst. We found that using exo-6, the stereocontrol $\left(\mathrm{P}_{\mathrm{m}}=0.96\right)$ was slightly better than when using endo-6 $\left(\mathrm{P}_{\mathrm{m}}=0.90\right)$. These observation is in good agreement with previous results where exo-6 showed higher kinetic resolution than endo-6 in aldol reactions. ${ }^{27}$ Finally we performed the polymerization of rac-LA in the presence of exo-6 and endo-6 (Table 1, entry 13). In this case we were able to get a good control over the polymerization but the isotactic selectivity was much lower than in previous cases. 
To further confirm the excellent stereocontrol observed in the ROP processes, the specific rotations values $[\alpha]$ and the thermal properties of the synthesized PLA were investigated. ${ }^{38}$ Hence, starting from racemic lactide (rac-LA) when proline endo-6 is used as catalyst (Table 1, entry 9), the value of the obtained polymers is $[\alpha]_{D}=75.9$ (Figure 4). This value is in good agreement with that of the PDLA polymer (Table 1, entry 10). Meanwhile using the diastereoisomeric proline exo-6 the $\alpha$ value is $[\alpha]_{D}=-79.6$ in agreement with the values measured for PLLA and confirming the ability of obtaining opposite outcomes switching the endo/exo diastereomeric nature of the catalyst. Furthermore, differential scanning calorimetry (DSC) analyses confirmed the crystalline character of the polymer obtained from rac-LA. For instance, the PLLA (Table 1, entry 12) showed a melting temperature of $165{ }^{\circ} \mathrm{C}$, and enthalpy values of $31 \mathrm{~J} / \mathrm{g}$ similar to the ones reported in the literature for isotactic PLLA. ${ }^{15}$

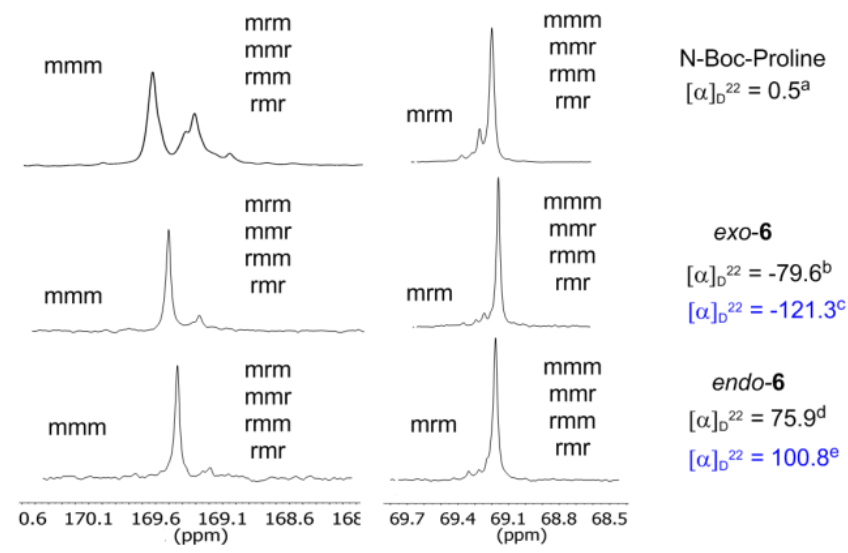

Figure 4. Carbonyl region (170-168 ppm) and methine region (70-67 ppm) of ${ }^{13} \mathrm{C}$ NMR spectra of poly(rac-LA) obtained using 3 different prolines as catalyst showing the different tetrads and specific rotation values $[\alpha]$ for the polymers obtained in Table $1\left(^{\mathrm{a}}\right.$ corresponds to Entry 3, ${ }^{\mathrm{b}}$ corresponds to Entry 7, ${ }^{\mathrm{c}}$ corresponds to Entry 6, ${ }^{\mathrm{d}}$ corresponds to Entry 9 and ${ }^{\mathrm{e}}$ corresponds to Entry 10). ${ }^{39}$

All these results confirmed that our highly substituted prolines not only provided polymers with low dispersities and molecular weights that closely track the monomer-to-initiator ratio, but also that depending on the remote substituent chirality, different polymeric stereochemical outcomes could be promoted.

These results indicate that the chirality of the catalyst can be transferred in an efficient way to the polymer. In order to gain a better understanding of the origins of this transfer, we performed experimental and computational studies on the nature of the reactants and their interactions before and during the polymerization process. We first analyzed the structure and dynamics of exo-6 by ${ }^{1} \mathrm{H}$ NMR diffusion ordered spectroscopy ${ }^{40-}$ ${ }^{42}$ (DOSY) experiments. The DOSY spectra of exo-6 at $0.25 \mathrm{M}$ and $1 \mathrm{M}$ concentrations (Figure 5a) showed different diffusion coefficients, thus indicating aggregation phenomena. At $1 \mathrm{M}$ concentration of exo-6, the measured $D_{1 \mathrm{M}}$ value resulted to be associated with a heavier species, whereas the $D_{0.25 \mathrm{M}}$ coefficient corresponded to a more mobile smaller structure. According to the Stokes-Einstein equation ${ }^{40}$ and assuming similar shape parameters for both species, we obtained the following ratio between the respective hydrodynamic radii of exo-6 at both concentrations:

$$
\frac{D_{0.25 M}}{D_{1 M}} \quad \frac{r_{1 M}}{r_{0.25 M}}=2.08
$$

This result suggested that if the dominant species at $0.25 \mathrm{M}$ concentration is monomeric exo-6, the major aggregate at $1 \mathrm{M}$ is the dimer. We analyzed this result by computational methods. Density functional theory (DFT) calculations performed in dichloromethane at the $\mathrm{M} 062 \mathrm{X}(\mathrm{PCM}) / 6-31+\mathrm{G}(\mathrm{d}, \mathrm{p})$ level of theory ${ }^{43-46}$ showed that formation of dimer d1 from exo-6 is an almost energetically degenerated process with $\Delta \mathrm{E}=-0.02 \mathrm{kcal} / \mathrm{mol}$ :
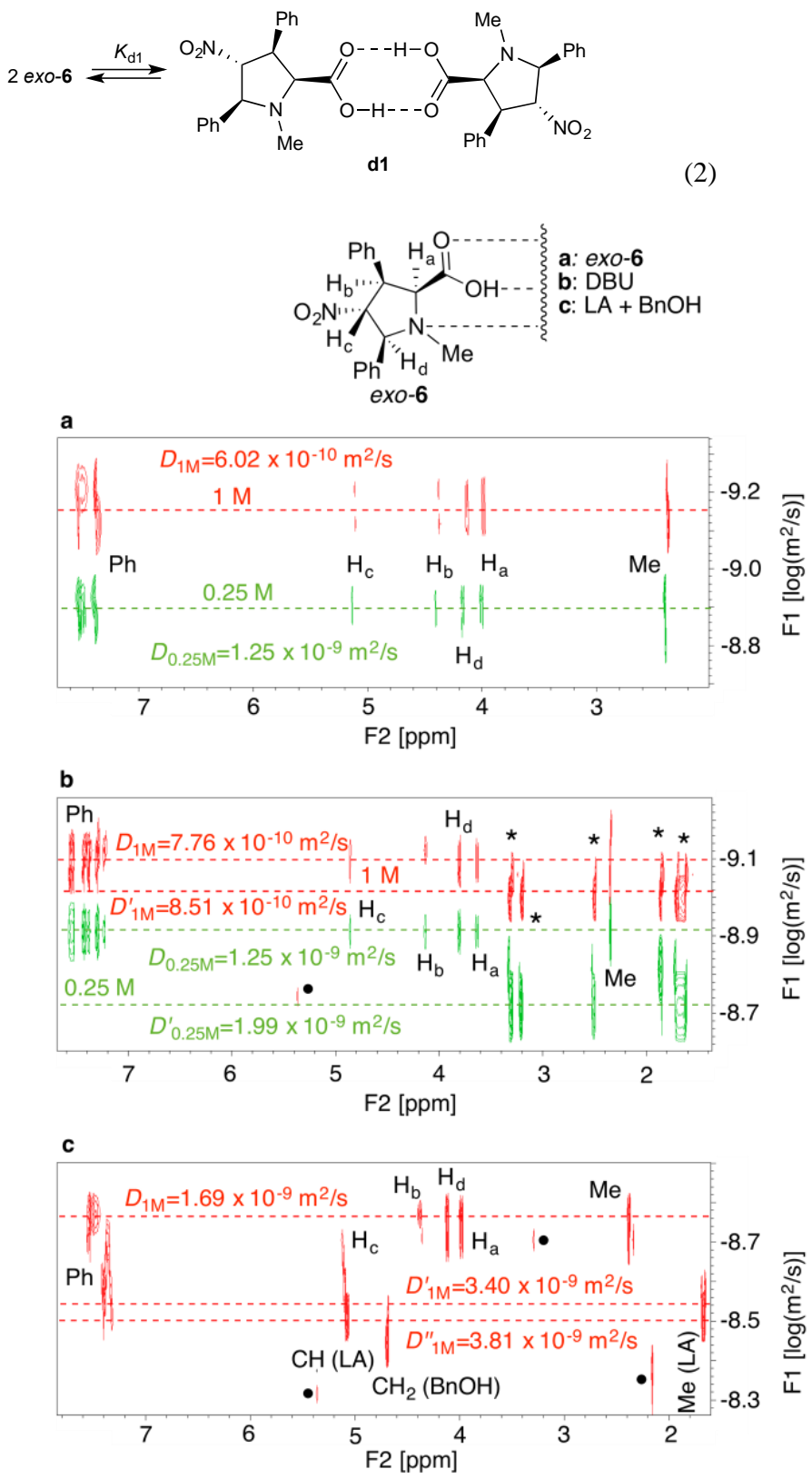

Figure 5. DOSY spectra of (a) exo-6 at $1 \mathrm{M}$ (red) and $0.25 \mathrm{M}$ (green) concentrations in deuterated dichloromethane; (b) exo-6 and DBU mixtures at the same concentrations; and (c) exo-6, lactide (LA) and benzyl alcohol $(\mathrm{BnOH})$. The DOSY signals associated with DBU are indicated as asterisks. The residual signals corresponding to other solvents such as non-deuterated dichloromethane, acetone and water are highlighted as dots. The diffusion coefficients $D$ (in $\mathrm{m}^{2} / \mathrm{s}$ ) are indicated for each component.

We next measured the effect of DBU on the behavior of exo6. Figure $5 \mathrm{~b}$ shows the DOSY spectra of the exo-6/DBU pairs at $1 \mathrm{M}$ and 0.25 concentrations. Our results indicate that the 
interaction of DBU with exo-6 is weaker since both species diffuse closely but not as a unique complex. Thus, the $D_{1 \mathrm{M}}$ value of exo-6 is close to (but larger than) that measured in the previous experiments. However, at the concentration of $0.25 \mathrm{M}$ the $D_{0.25}$ value of exo-6 is identical to that found in the absence of DBU (vide supra). As far as DBU is concerned, the corresponding $D_{1 \mathrm{M}}$ value was found to be lower than $D_{0.25}$. This latter value was almost identical to that measured for free DBU $\left(D_{\mathrm{DBU}}=1.66 \times 10^{-9}\right.$ $\mathrm{m}^{2} / \mathrm{s}$ ). DFT calculations permitted the characterization of a weak exo-6/DBU complex d2 (eq. 2), whose associated equilibrium constant was calculated to be close to that corresponding to an isoenergetic transient-complexation process $\left(K_{\mathrm{d} 2}=0.93 \mathrm{M}^{-1}\right)$ :

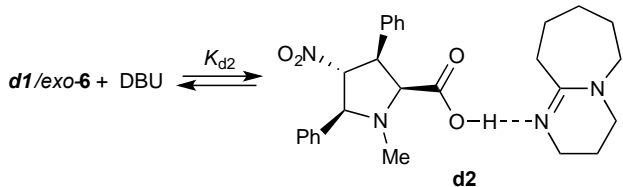

This result is compatible with the loose interaction between exo-6 and DBU detected by the DOSY experiments. The possibility of an ionic pair $\mathbf{d} \mathbf{3}$ formed by the acid/base interaction between both components was also analyzed (eq. 4):

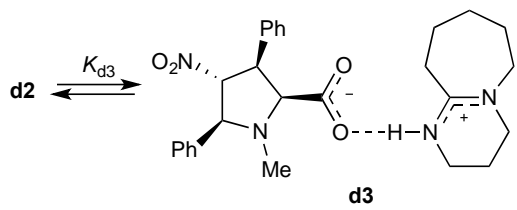

Our calculations indicated that in dichloromethane solution both pairs are almost isoenergetic with $K_{\mathrm{d} 3}=0.95$, in which $\mathbf{d} 2$ is the major species. In fact, ionic pair $\mathbf{d 3}$ should result in a tighter complex, thus promoting a more coherent diffusion, which was not suggested by the DOSY experiments.

From these results we concluded that the presence of DBU can modify the dimeric structure of exo-6 at a concentration of $1 \mathrm{M}$ in dichloromethane, but it does not alter significantly the ability of exo-6 to participate in the catalytic cycle associated with the polymerization process. Actually, DOSY experiments including a mixture of exo-6, lactide and benzyl alcohol (total concentration: $1 \mathrm{M})$ showed a slight modification in the dynamic behavior of exo6 (Figure 5c). Although on average the three components of the mixture moved separately, the $D_{1 \mathrm{M}}$ value for exo-6 corresponds to a lighter monomeric species that can interact with the reactants to trigger the polymerization process. Therefore, this latter neutral $\mathrm{N}$-methyl amino acid can be considered explicitly as the active chiral organocatalyst in the polymerization process.

Additional DFT calculations were conducted to investigate the origin of the enantiomeric site control of the polymerization process. Although different proposals for organocatalytic ROP reactions have been reported, ${ }^{47,48}$ no precedent exists for our catalytic system. On the basis of computational studies for related transesterification processes ${ }^{34,49,50}$ as well as on the previous DOSY and computational experiments (vide supra), the catalytic cycle gathered in Figure 6 can be proposed, which relies on the preferential coordination of D-LA or L-LA with catalysts 6 (vide supra). Since chiral discrimination is required to promote the reaction of LA with an alcohol (benzyl alcohol in the first catalytic cycle, see Figure 5a), interaction of LA with the acidic part of organocatalysts 6 results in LUMO activation that enhances the electrophilicity of the substrate. In addition, the alcohol can be activated by increasing the energy of its HOMO by means of the interaction of the hydroxy group with the tertiary amine moiety of 6 (Figure 6). Of course, DBU can move around the active sites of catalysts $\mathbf{6}$. However, as demonstrated in the previous DOSY and computational experiments, interaction of monomeric neutral organocatalysts 6 with $\mathrm{LA}$ and $\mathrm{MeOH}$ captures the essential aspects of the origins of the stereocontrol.

Dual activation of INT1 results in the formation of intermediate INT2, in which the tetrahedral intermediate derived from the nucleophilic attack of the alcohol on LA is stabilized by hydrogen bonding with the zwitterionic tautomer of organocatalyst 6 (Figure 6a). Intermediate INT2 is converted into alcohol INT3 with the assistance of DBU or the 6/DBU pair. This latter intermediate enters the next catalytic cycle to proceed with the polymerization process. Iteration of this cycle results in the elongation of the polymeric chiral chain. This mechanism requires chiral discrimination only at the INT1 $\rightarrow$ INT2 step. Therefore, the interaction between catalysts 6 and D-LA or L-LA will determine the stereo regularity of the corresponding polymers. DFT calculations at the MO6-2X(PCM)/6-31+G(d,p)//B3LYP/6$31 \mathrm{G}(\mathrm{d})$ level of theory ${ }^{43,46}$ using methanol as model nucleophilic alcohol were carried out in order to get a better understanding of the origins of the stereoselection between L-LA and D-LA by exo-6 and endo-6, respectively. Since the pyrrolidine ring of both organocatalysts can adopt different conformations, all the possible energetically available conformers of endo-6 and exo-6 compounds were explored. In particular, we found that whereas the most stable conformations included both carboxy and 5phenyl moieties in equatorial disposition, the $N$-methyl group can be either in equatorial or axial orientations with respect to the carboxy group, denoted in Figure $5 \mathrm{~b}$ as anti and syn conformations, respectively. The above mentioned interactions of the amino and carboxy groups with the alcohol and the lactide lead to quite different geometries for the respective complexes INT1, transition structures, and addition products INT2 (see the SI for further details). In particular, our calculations showed that INT2 regenerates catalyst exo-6 in its neutral form, an energetically favoured process (see Figure S44 of the SI).

In the case of exo-6, the saddle point of lowest energy, denoted as exo,anti-TS in Figure 6c, exhibited an equatorial $N$-methyl group with a preference for L-LA of $0.9 \mathrm{kcal} / \mathrm{mol}$ in terms of Gibbs energy with respect to D-LA. This difference in free energy corresponds to a $(S, S):(R, R)$ discrimination ratio of $83: 17$, a value in excellent agreement with the experimentally found value of 86:14 (see the SI for further information). In contrast, when the reaction coordinate of endo-6 was studied, it was found that saddle point endo, syn-TS with an axial $N$-methyl group, and DLA as substrate, was the less energetic one, the endo,anti-TS with L-LA as substrate being $0.30 \mathrm{kcal} / \mathrm{mol}$ higher in energy. This value corresponds to a $(S, S):(R, R)$ discrimination ratio of $38: 62$, also in good agreement with the experimentally found value of 30:70 (Figure 3b,c). These results are compatible with the mechanistic proposal consisting of a nucleophilic attack of the activated alcohol on the corresponding chiral LA, whose electrophilicity is enhanced by the chiral carboxy group of the organocatalysts. These attacks are quite synchronous (Figure 6c) in terms of formation of the new $\mathrm{C}-\mathrm{C}$ bond and proton motion from the alcohol to the catalyst and from the carboxy group to the lactide. This high density of chiral an prochiral centres results in a high selectivities of exo-6 and endo-6 towards L-LA and D-LA, respectively. In addition, our calculations reproduce correctly two relevant experimental findings: (i) both catalysts exo-6 and endo-6 give rise to opposite stereochemical outcomes; and (ii) exo-6 is more stereoselective than its endo congener.

\section{Conclusions}

In summary, we report a highly efficient organic catalytic 
system for the stereocontrolled ROP of rac-LA. We have found that by switching from endo to exo configuration in unnatural densely substituted proline $\mathbf{6}$, the chirality of the catalyst is transferred efficiently to the polymer, thus obtaining different stereochemical outcomes. Hence, when endo-6 was used, it preferentially promoted the polymerization of D-LA, whereas exo-6 polymerized preferentially L-LA from a racemic mixture of L- and D- stereoisomers. Mechanistic and computational studies reveal the importance of the configuration of the densely substituted aminoacids to

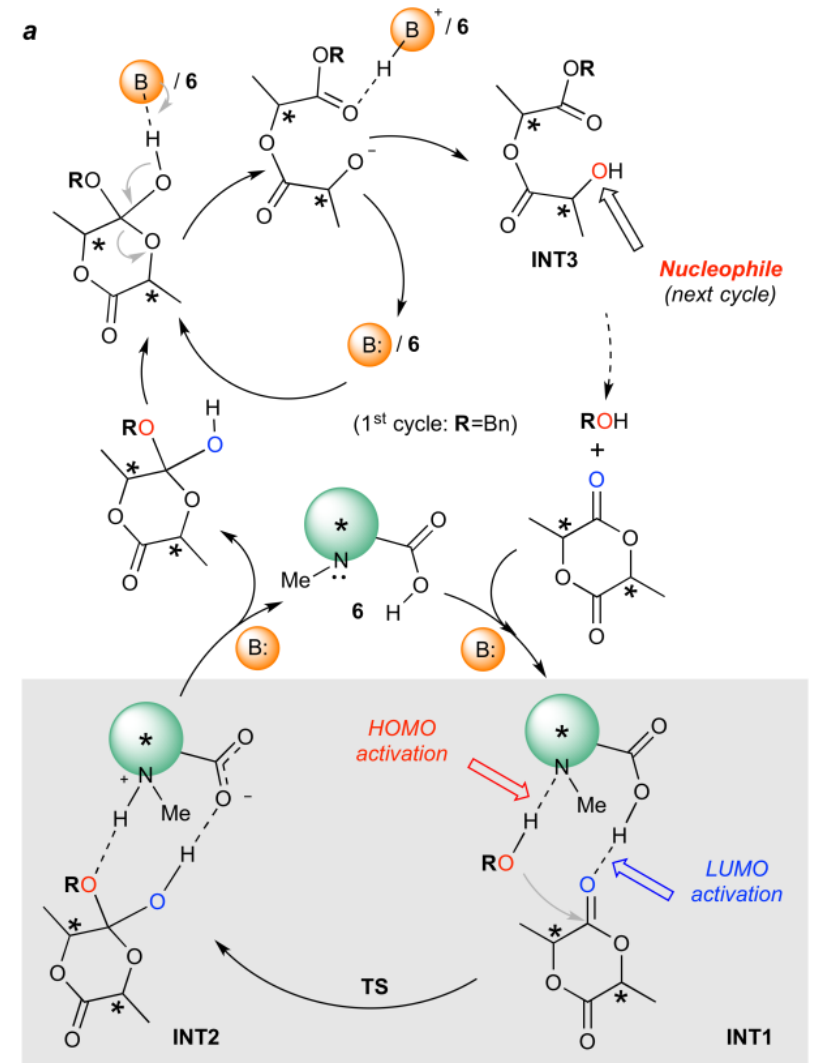

b
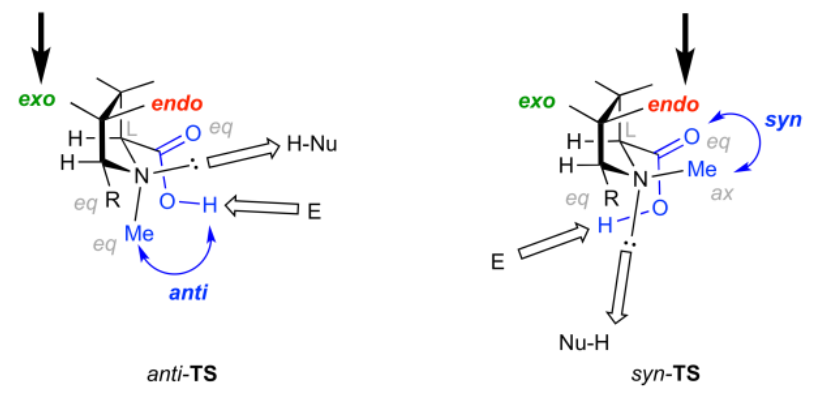

c

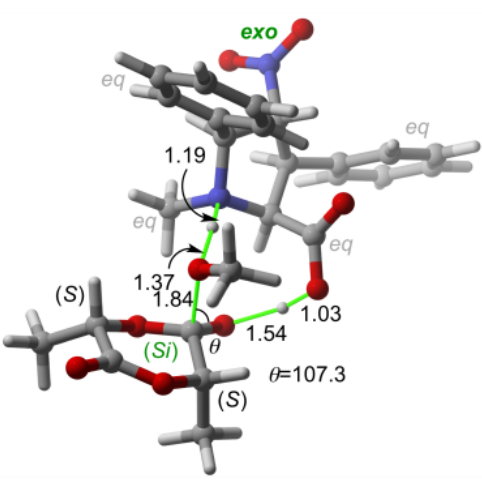

exo, anti-TS

(preferred Si attack on (S,S)-lactide)

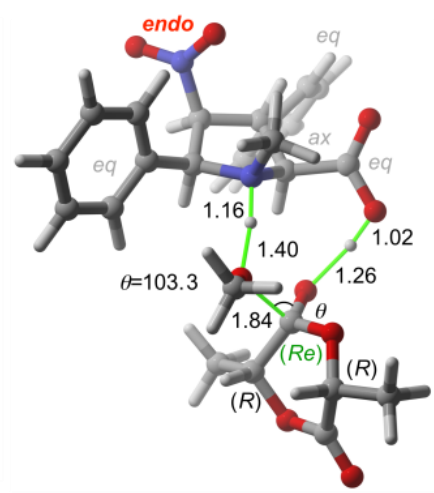

endo,syn-TS

(preferred Re attack on $(R, R)$-lactide)

Figure 6. a) Proposed catalytic cycle for the ROP of $(R, R)$-D-lactide and $(S, S)$-L-lactide. Notice the dual activation of the nucleophilic alcohol and electrophilic lactide, as well as the chiral discrimination induced by catalysts 6 . b) Possible interaction patterns depending upon the syn/anti relationship between the carboxylic acid (in equatorial disposition) and $N$-methyl group (in axial or equatorial dispositions) of organocatalysts 6. c) Optimized geometries (B3LYP/6-31G(d) level of theory) of preferred transition structures TS associated with the interaction between methanol (as a model primary alcohol) and lactide in the presence of exo-6 (exo, anti-TS) and endo-6 (endo, syn-TS). Distances and angles given in $\AA$ and deg. respectively. Relative energies were computed at the M062X(PCM)/6$31+\mathrm{G}(\mathrm{d}, \mathrm{p}) / / \mathrm{B} 3 \mathrm{LYP} / 6-31 \mathrm{G}(\mathrm{d})$ level of theory, in which dichloromethane was included in the PCM calculations

promote the stereocontrolled polymerization. This strategy of using combined enantiopure unnatural organocatalyst/organic base pairs could be readily extended to other stereocontrolled metal-free polymerization processes.

\section{Experimental Section}

Preparation of exo-6. A solution of chiral ligand NMe-DEhuPhos-3b $(0.03 \mathrm{mmol})$ and $\mathrm{Cu}\left(\mathrm{CH}_{3} \mathrm{CN}_{4}\right) \mathrm{PF}_{6}(0.03 \mathrm{mmol})$ in $2.0 \mathrm{~mL}$ of dry THF was stirred at $-20{ }^{\circ} \mathrm{C}$ for 20 minutes. Then, a solution of imine $2 \mathbf{a}(0.9 \mathrm{mmol})$ in $3 \mathrm{~mL}$ of solvent, triethylamine $(7 \mathrm{~mL}, 0.05 \mathrm{mmol})$ and trans- $\beta$-nitrostyrene $1(1 \mathrm{mmol})$ in $3 \mathrm{~mL}$ of solvent were consecutively added. After reaction completion, the mixture was filtered through a celite pad and the filtrate was concentrated under reduced pressure and purified by silica gel flash column chromatography. The corresponding exo-5b cycloadduct $(1.50 \mathrm{mmol})$ and 1,3,5-trioxane $(4.50 \mathrm{mmol})$ were dissolved in $2.5 \mathrm{~mL}$ of dry dichlorometane and trifluoroacetic acid
$(1.2 \mathrm{~mL})$ and $\mathrm{Et}_{3} \mathrm{SiH}(2.44 \mathrm{~mL}, 15.0 \mathrm{mmol})$ were added subsequently. The mixture was stirred at room temperature for 48h. The, water was added and the mixture was extracted three times with $\mathrm{CH}_{2} \mathrm{Cl}_{2}$. The combined organic layers were dried and concentrated under reduced pressure to yield crude exo-5a. Finally, to a solution of exo-5a $(1.45 \mathrm{mmol})$ in acetone $(4.5 \mathrm{~mL})$ stirred at room temperature a solution of sodium hydroxide (3.12 mmol) in water $(4.5 \mathrm{~mL})$ was added. The reaction mixture was stirred for $16 \mathrm{~h}$ and acidified with $2 \mathrm{~N} \mathrm{HCl}$ to $\mathrm{pH} \approx 2$. A solid precipitated from the solution and was filtered, washed with water and dried under vacuum to afford the desired product exo-6. Yield: $85 \%$. Yellow syrup. $[\alpha]_{\mathrm{D}}^{25}=+48.6$ ( $c$ 0.33, acetone). FTIR (neat, $\left.\mathrm{cm}^{-1}\right): 1550,700 .{ }^{1} \mathrm{H}$ NMR $\left(400 \mathrm{MHz}\right.$, Acetone- $\left.d_{6}\right) \delta 7.61$ (d, $J=7.4 \mathrm{~Hz}, 2 \mathrm{H}$ ), 7.47 (ddd, $J=19.5,14.4,7.0 \mathrm{~Hz}, 6 \mathrm{H}$ ), 7.32 $(\mathrm{q}, J=7.1 \mathrm{~Hz}, 2 \mathrm{H}), 5.19(\mathrm{t}, J=7.6 \mathrm{~Hz}, 1 \mathrm{H}), 4.44(\mathrm{dd}, J=9.5,6.9$ $\mathrm{Hz}, 1 \mathrm{H}), 4.23(\mathrm{~d}, J=8.4 \mathrm{~Hz}, 1 \mathrm{H}), 4.14(\mathrm{~d}, J=9.5 \mathrm{~Hz}, 1 \mathrm{H}), 2.41$ (s, 3H). HRMS (ESI) for $\mathrm{C}_{18} \mathrm{H}_{18} \mathrm{~N}_{2} \mathrm{O}_{4}$ calculated $[\mathrm{M}+\mathrm{H}]^{+}$: 327.1267. Found: 327.1338 . 
Preparation of endo-6. A solution of chiral ligand NMe-LEhuPhos-3a $(0.03 \mathrm{mmol})$ and $\mathrm{Cu}\left(\mathrm{CH}_{3} \mathrm{CN}\right)_{4} \mathrm{PF}_{6}(0.03 \mathrm{mmol})$ in 2.0 $\mathrm{mL}$ of dry THF was stirred at $-60{ }^{\circ} \mathrm{C}$ for 15 minutes. Then, a solution of imine $\mathbf{2 b}(0.9 \mathrm{mmol})$ in $3.0 \mathrm{~mL}$ of solvent, triethylamine $(7 \mathrm{ml}, 0.05 \mathrm{mmol})$ and the corresponding nitroalkene $1(0.50 \mathrm{mmol})$ in $1.0 \mathrm{~mL}$ of solvent were successively added. After reaction completion, the mixture was filtered through a celite pad and the filtrate was concentrated under reduced pressure and purified by silica gel flash column chromatography. The corresponding endo-5b cycloadduct $(1.50 \mathrm{mmol})$ and $1,3,5-$ trioxane $(4.50 \mathrm{mmol})$ were dissolved in $2.5 \mathrm{~mL}$ of dry dichlorometane and trifluoroacetic acid $(1.2 \mathrm{~mL})$ and $\mathrm{Et}_{3} \mathrm{SiH}(2.44$ $\mathrm{mL}, 15.0 \mathrm{mmol}$ ) were added subsequently. The mixture was stirred at room temperature for $48 \mathrm{~h}$. Then, TFA $(11 \mathrm{~mL})$ was added. After $16 \mathrm{~h}$ water was added and the mixture was extracted three times with $\mathrm{CH}_{2} \mathrm{Cl}_{2}$. The combined organic layers were dried and concentrated under reduced pressure. The crude mixture was purified by precipitation with $\mathrm{Et}_{2} \mathrm{O}$ to obtain endo-6. Yield: $57 \%$. Pale yellow syrup. $[\alpha]_{\mathrm{D}}{ }^{25}=+20.81(c 0.85$, acetone). FTIR (neat, $\left.\mathrm{cm}^{-1}\right): 3055,2925,2854,1719,1554,1264,732,700 .{ }^{1} \mathrm{H}$ NMR $\left(400 \mathrm{MHz}\right.$, Acetone- $\left.d_{6}\right) \delta 7.52(\mathrm{~d}, J=7.2 \mathrm{~Hz}, 2 \mathrm{H}), 7.46(\mathrm{~d}, J=7.6$ $\mathrm{Hz}, 2 \mathrm{H}), 7.36(\mathrm{dt}, J=20.0,7.4 \mathrm{~Hz}, 6 \mathrm{H}), 5.64-5.54(\mathrm{t}, J=8.1 \mathrm{~Hz}$, $1 \mathrm{H}), 4.52(\mathrm{~d}, J=8.7 \mathrm{~Hz}, 1 \mathrm{H}), 4.50-4.47(\mathrm{~m}, 1 \mathrm{H}), 3.61(\mathrm{~d}, J=9.5$ $\mathrm{Hz}, 1 \mathrm{H}), 2.37$ (s, 3H). HRMS (ESI) for $\mathrm{C}_{18} \mathrm{H}_{18} \mathrm{~N}_{2} \mathrm{O}_{4}$ calculated [M $+\mathrm{H}]^{+}:$327.1267. Found: 327.1345.

Polymerization of rac-lactide (rac-LA). Polymerizations were carried out in nitrogen filled glove box. In a typical procedure, rac-lactide was polymerized using a mixture of the densely substituted proline exo-6 or endo-6 and 1,8diazabicyclo[5.4.0] undec-7-ene (DBU) co-catalyst. In brief, raclactide $(0.3 \mathrm{~g}, 2.08 \mathrm{mmol}, 50$ equiv) benzyl alcohol $(4.4 \mu \mathrm{L}, 0.042$ mmol, 1 equiv) (for a degree of polymerization of 50) were charged in a $20 \mathrm{~mL}$ vial. Afterwards, dicloromethane was added and the concentration was adjusted to $1 \mathrm{M}$. To initiate the polymerization, densely substituted proline $(0.014 \mathrm{~g}, 0.042 \mathrm{mmol}$, 1 equiv) and DBU (0.0063 g, $0.042 \mathrm{mmol}, 1$ equiv) were added. After $24 \mathrm{~h}$, the polymerization was quenched with excess of benzoic acid and the crude product was precipitated in cold methanol. The collected polymer was dried under vacuum at 35 ${ }^{\circ} \mathrm{C}$ until a constant weigh was reached. Yield, $0.14 \mathrm{~g} \mathrm{(45 \% ).} \mathrm{Size}$ exclusion chromatography (SEC): $\mathrm{Mn}=3300 \mathrm{~g} / \mathrm{mol}$, dispersity $(Đ)=1.10,{ }^{1} \mathrm{H} \mathrm{NMR}\left(\mathrm{CDCl}_{3}\right) 7.35$ (ArH, Initiator) $5.21(\mathrm{CH}, 2 \mathrm{H})$, $1.42\left(\mathrm{CH}_{3}, 6 \mathrm{H}\right)$.

\section{ASSOCIATED CONTENT}

\section{Supporting Information}

Experimental procedure and characterization of compounds, ORTEP diagrams and computational details. This material is available free of charge via the Internet at http://pubs.acs.org.

\section{AUTHOR INFORMATION}

\section{Corresponding Author}

*Email: david.mecerreyes@ehu.es

*Email: fp.cossio@ehu.es

\section{ORCID}

Fernando P. Cossío: 0000-0002-4526-2122

\section{Author Contributions}

$\$$ These authors contributed equally to this work.

\section{Notes}

The authors declare no competing financial interests.

\section{ACKNOWLEDGMENT}

Financial support of this research by the MINECO (CTQ201680375-P, Consolider CTQ2016-81797-REDC, SUSPOL and FDI 16507) the Gobierno Vasco/Eusko Jaurlaritza (Grant IT673-13 and IT618-13), the University of the Basque Country UPV/EHU (UFI 11/22 QOSYC), and the European Commission (SUPSOLEJD 642671) is gratefully acknowledged. A. Sanchez-Sanchez thanks the post-doctoral funding for doctoral Research Staff Improvement of Basque Government grant

\section{REFERENCES}

(1) Coates, G. W. Chem. Rev.2000, 100, 1223.

(2) Stanford, M. J.; Dove, A. P. Chem. Soc. Rev.2010, 39, 486.

(3) Hawker J.C.; Wooley K.L. Science. 2005, 5738,1200.

(4) Natta, G.; Pino, P.; Corradini, P.; Danusso, F.; Mantica, E.; Mazzanti, G.; Moraglio, G. J. Am. Chem. Soc.1955, 77, 1708.

(5) Ovitt, T. M.; Coates, G. W. J. Am. Chem. Soc.2002, 124, 1316.

(6) Jensen, T. R.; Breyfogle, L. E.; Hillmyer, M. A.; Tolman, W. B. Chem. Commun.2004, 2504.

(7) Mou, Z.; Liu, B.; Liu, X.; Xie, H.; Rong, W.; Li, L.; Li, S.; Cui, D. Macromolecules. 2014, 47, 2233.

(8) Carpentier, J.-F. Macromol. Rapid Commun.2010, 31, 1696.

(9) Lecomte, P.; Jérôme, C. In Synthetic Biodegradable Polymers; Rieger, B., Künkel, A., Coates, W. G., Reichardt, R., Dinjus, E., Zevaco, A. T., Eds.; SpringerBerlin Heidelberg: Berlin, Heidelberg, 2012, p 173.

(10) Zhang, X.; Jones, G. O.; Hedrick, J. L.; Waymouth, R. M. Nat. Chem.2016, 8, 1047.

(11) Thomas, C. M. Chem. Soc. Rev.2010, 39, 165.

(12) Miyake, G. M.; Chen, E. Y. X. Macromolecules. 2011, 44,

4116.

(13) Zhong, Z.; Dijkstra, P. J.; Feijen, J. J. Am. Chem. Soc.2003, $125,11291$.

(14) Dechy-Cabaret, O.; Martin-Vaca, B.; Bourissou, D. Chem. Rev.2004, 104, 6147.

(15) Ottou, W. N.; Sardon, H.; Mecerreyes, D.; Vignolle, J.; Taton, D. Prog. Polym. Sci.2016, 56, 64.

(16) Kiesewetter, M. K.; Shin, E. J.; Hedrick, J. L.; Waymouth, R. M. Macromolecules. 2010, 43, 2093.

(17) Dove, A. P.; Li, H.; Pratt, R. C.; Lohmeijer, B. G. G.; Culkin, D. A.; Waymouth, R. M.; Hedrick, J. L. Chem. Commun.2006, 2881.

(18) Fevre, M.; Pinaud, J.; Gnanou, Y.; Vignolle, J.; Taton, D. Chem. Soc. Rev.2013, 42, 2142.

(19) Zhang, L.; Nederberg, F.; Messman, J. M.; Pratt, R. C.; Hedrick, J. L.; Wade, C. G. J. Am. Chem. Soc.2007, 129, 12610.

(20) Makiguchi, K.; Yamanaka, T.; Kakuchi, T.; Terada, M.; Satoh, T. Chem. Commun.2014, 50, 2883.

(21) Zhu, J. B.; Chen, E. Y. X. J. Am. Chem. Soc. 2015, 137, 12506.

(22) Ahrendt, K. A.; Borths, C. J; MacMillan, D. W. C. J. Am. Chem. Soc. 2000, 122, 4243.

(23) Jarvo, E. R. \& Miller, S. J. Tetrahedron. 2002, 58, 2481.

(24) List, B. Tetrahedron. 2002, 58, 5573.

(25) List, B., Lerner, R. A. \& Barbas, C. F. J. Am. Chem. Soc. 2000, $122,2395$.

(26) Ruiz-Olalla, A.; Retamosa, M. d. G.; Cossío, F. P. J. Org. Chem.2015, 80, 5588 .

(27) Conde, E.; Bello, D.; de Cozar, A.; Sanchez, M.; Vazquez, M. A.; Cossio, F. P. Chemical Science.2012, 3, 1486.

(28) Yang, J. W.; Chandler, C.; Stadler, M.; Kampen, D.; List, B. Nature. 2008, 452, 453.

(29) Palomo, C.; Vera, S.; Mielgo, A.; Gómez-Bengoa, E. Angew. Chem. Int. Ed.2006, 45, 5984.

(30) List, B.; Pojarliev, P.; Martin, H. J. Org. Lett.2001, 3, 2423.

(31) Ramachary, D. B.; Chowdari, N. S.; Barbas, C. F. Angew. Chem. Int. Ed.2003, 42, 4233 . 
(32) Liu, N.; Martin, A.; Robert, F.; Vincent, J.-M.; Landais, Y.; Vignolle, J.; Cramail, H.; Taton, D. Macromolecules. 2014, 47, 525.

(33) Liu, J.; Liu, L. Macromolecules. 2004, 37, 2674.

(34) Coady, D. J.; Fukushima, K.; Horn, H. W.; Rice, J. E.; Hedrick, J. L. Chem. Commun.2011, 47, 3105.

(35) It is worth nothing that after the conditions for the polymerization were surveyed in terms of different solvents (DCM, THF and DMF) and differen tcatalyst concentrations (1, 5, 10, $20 \mathrm{~mol} \%$ respect to the initiator), the best results in terms of end-group fidelity were obtained using DCM and initial initiator-to-catalyst ratio of $5 \mathrm{~mol} \%$ (Table S2).

(36) Coudane, J.; Ustariz-Peyret, C.; Schwach, G.; Vert, M. J. Polym. Sci., Part A: Polym. Chem.1997, 35, 1651.

(37) de Gracia Retamosa, M.; de Cózar, A.; Sánchez, M.; Miranda, J. I.; Sansano, J. M.; Castelló, L. M.; Nájera, C.; Jiménez, A. I.; Sayago, F. J.; Cativiela, C.; Cossío, F. P. Eur. J. Org. Chem. 2015, 2015, 2503.

(38) Wisniewski, M.; Borgne, A. L.; Spassky, N. Macromol. Chem. Phys.1997, 198, 1227.

(39) exchanging R by S same tetrads will be obtained.

(40) Macchioni, A.; Ciancaleoni, G. Z.; Zuccaccia, C.; Zuccaccia, D. Chem. Soc. Rev. 2008, 37, 479.

(41) Li, D.; Keresztes, I.; Hopson, R.; Williard, P. G. Acc. Chem. Res. 2009, 42, 270.
(43) (a) Zhao, Y.; Truhlar, D. G. Theor. Chem. Acc.2008, 119, 525. (b) (Zhao, Y.; Truhlar, D. G. Theor. Chem. Acc. 2008, 120, 215. (b) Zhao, Y.; Truhlar, D. G. Acc. Chem. Res. 2008, 41, 157.

(44) (a) Becke, A. D. J. Chem. Phys. 1993, 98, 5648. (b) Lee, C. Yang, W.; Parr, R. G. Phys. Rev. B 1998, 37, 785. (c) Vosko, S. H.; Wilk, L.; Nusair, M. Can. J. Phys. 1980, 58, 1200.

(45) Cammi, R.; Mennucci, B.; Tomasi, J. J. Phys. Chem. A. 2000, $104,5631$.

(46) Gaussian 09, Revision D.01; Gaussian, Inc., Wallingford, CT, 2009 .

(47) Fastnacht, K. V.; Spink, S. S.; Dharmaratne, N. U.; Pothupitiya, J. U.; Datta, P. P.; Kiesewetter, E. T.; Kiesewetter, M. K. ACS Macro Lett.2016, 5, 982.

(48) Kadota, J.; Pavlović, D.; Desvergne, J.-P.; Bibal, B.; Peruch, F.; Deffieux, A. Macromolecules.2010, 43, 8874

(49) Horn, H. W.; Jones, G. O.; Wei, D. S.; Fukushima, K.; Lecuyer, J. M.; Coady, D. J.; Hedrick, J. L.; Rice, J. E. J. Phys. Chem. A.2012, 116, 12389.

(50) Bonduelle, C.; Martín-Vaca, B.; Cossío, F. P.; Bourissou, D. Chem. Eur. J.2008, 14, 5304. 